\title{
Modeling and Simulation of AMT with MWorks
}

\author{
Ming Jiang, Jiangang Zhou, Wei Chen, Yunqing Zhang, Liping Chen \\ CAD Center, Huazhong University of Science and Technology, China \\ zhangyq@hust.edu.cn
}

\begin{abstract}
This paper presents a detailed AMT model composed of various components from multi-domains like mechanical systems (clutch, gear pair, synchronizer, etc.), pneumatic actuator systems (clutch actuation system, gear select actuation system, gear shift actuation system, etc.). The model is implemented using the Modelica modeling language in an objectoriented environment. The Modeling and simulation of the AMT model was carried out on MWorks, which is developed by Huazhong University of Science and Technology.
\end{abstract}

Keywords: modeling; simulation; automatic mechanical transmission (AMT); multi-domain;

\section{Introduction}

The automatic mechanical transmission (AMT) is generally constituted by a dry clutch and a multispeed gearbox, both equipped with hydraulic, pneumatic or electric actuators, which are driven by an Electronic Control Unit (ECU). Compared to manual transmission, the AMT allows to improve driving comfort and shift quality, and can get better fuel economy. Compared to automatic transmission (AT), The AMT has the advantage of lower weight and higher efficiency [1]. And moreover, the product line of manual transmission can be reused for AMT. So the AMT has attracted increasing interesting from automotive researches, and the vehicles equipped AMT are spreading in recent years, especially in Europe, Japan and China.

The AMT always uses electronic sensors, processors and hydraulic, pneumatic or electric actuators to execute clutch actions and gear shifts on the command of the driver [2,3]. The clutch and gearbox are controlled by electronic computers and hydraulic, pneumatic or electric actuators. The AMT operates the clutch and throttle to match velocity according to the control logic. Such systems coupled with various physical domains have great influence on the dynamic behavior of the vehicle, such as shift quality, dri- veability, fuel economy, acceleration, etc.[4]. Many researches have been carried out to study the dynamic performance and control logic of the AMT systems. However, many previous works considered the AMT actuation system as an ideal system and neglected the transient behavior of the clutch actuation gear box actuation due to time delays, non-linear dynamic characteristic, external disturbance and parameter uncertainty of the pneumatic, hydraulic, mechanic and electric components $[5,6]$. The simplification of the clutch and gear box system can't represent a real AMT. The actuator dynamics cannot be neglected at all, since they can affect the clutch action and shifting performances. So some researchers built more detailed model to study the AMT system. Lucente [7] described detailed models of clutch electro-hydraulic and electro-mechanical actuators for AMT. Zhao [8] presented the modeling and simulation of clutch actuator, and addressed the analysis on the DC permanent magnet motor (power source). This paper presents a detailed an AMT model composed of various components from multidomains like mechanical systems (clutch, gear pair, synchronizer, etc.), pneumatic actuation systems (clutch actuation system, gear select actuation system, gear shift actuation system, etc.).

The model is implemented using the Modelica modeling language, which is a non-proprietary, objectoriented, equation based language to conveniently model complex physical systems containing, e.g., mechanical, electrical, electronic, hydraulic, thermal, control, electric power or process-oriented subcomponents [9]. The simulation was carried out by MWorks [10], which is developed by Huazhong University of Science and Technology.

The paper is organized as the follows. Section 2 introduces the modeling for clutch, including clutch plate, diaphragm spring, clutch lever and clutch damper, etc. Section 3 introduces the modeling for gear box, such as gear pairs, synchronizer, etc. The clutch actuator and gear actuator including pneumatic cylinder and valves, etc. are discussed in section 4. The simulation results and discussions are illustrated in section 5. Section 6 offers our conclusions and further study. 


\section{Clutch Model}

The function of an engaging friction clutch is to transmit torque gradually, to avoid high accelerations or jerks, when the engine is connected to the rest of the driveline. As can been seen in Fig.1, the clutch system is consists of clutch plate, diaphragm, throwout bearing, pressure plate, etc. The flywheel is connected to the engine, the clutch plate is connected to the transmission, and the clutch lever is connected to pneumatic clutch actuation system, which will be described in the following. When clutch actuator acted on the clutch lever, the throw-out bearing pushed the diaphragm spring in sequence, then the diaphragm spring pull the pressure plate apart away the clutch disc, which in turn release presses against the flywheel. So there is no torque transmit from the flywheel to the transmissions. And when the clutch actuation released, the diaphragm spring push the pressure plate against the clutch disc, which in turn presses against the clutch plate. This locks the engine to the transmission input shaft, making them spin at the same speed.

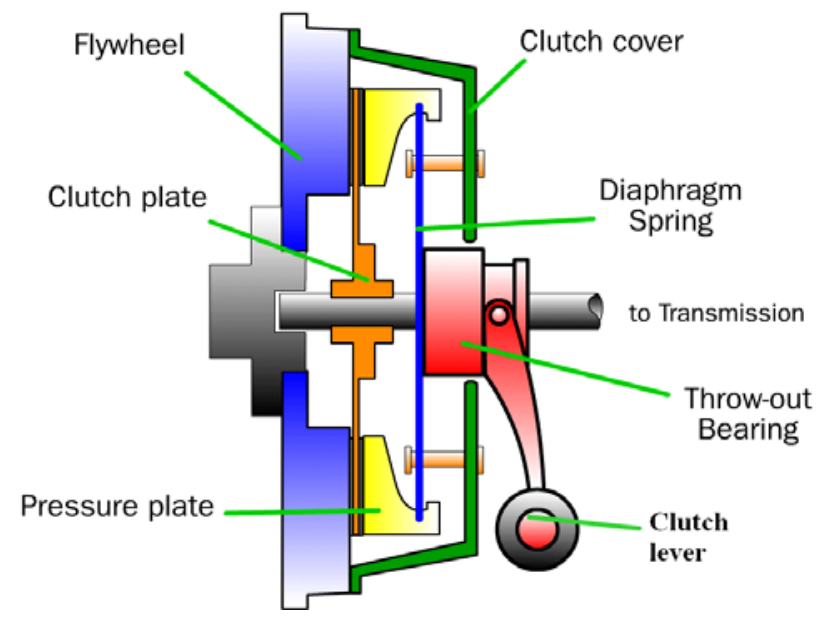

Fig. 1 The clutch system

\subsection{Clutch Plate}

According the function of the clutch, there are three distinct modes of operation of clutch plate: free, where the two plates transmit no torque; slipping, where the two plates have differing angular velocities; and lockup, where the two plates rotate together. The clutch system was analyzed using a lumpedparameter model.

The clutch plate model was developed based on clutch model included in Modelica standard library. The input signal u was designed as a normalized form in the standard library. In this paper, the normal force was designed as input signal.
The torque capacity of the clutch is a function of its size, friction characteristics, and the normal force that is applied [8].

$$
T_{f \max }=\mu F_{n} n\left(\frac{2}{3}\right)\left(\frac{R_{0}^{3}-R_{i}^{3}}{R_{0}^{2}-R_{i}^{2}}\right)
$$

Where $\mu$ is coefficient of friction that can be formulated as a function of clutch slip, $F_{n}$ is normal force on clutch face that depends on the apply pressure, $R_{o}$ is outside radius of friction disc, $R_{i}$ is inside radius of friction disc, $n$ is the number of friction discs.

\subsection{Diaphragm Spring}

The clutch plates are pushed together by diaphragm spring. However, it is difficult to give the equation of the diaphragm. In this paper, a lookup table based on experiment data is used to simulate the mechanical character diaphragm. A linear interpolation to the characteristic curve is used to model the diaphragm spring. The normal actuation force on the clutch plate through the model of diaphragm is acquired by the diaphragm model.

\subsection{Clutch Lever}

The clutch lever is modeled by lever principle, and described as follows:

$$
\begin{aligned}
& F_{A}=i^{*} F_{B} \\
& S_{A}=S_{B} / i
\end{aligned}
$$

Where, $F_{A}$ and $F_{A}$ are the force acted on the two sides, and $S_{A}$ and $S_{A}$ are the displacement of the two sides, and $i$ is the lever ratio.

\subsection{Clutch damper}

The clutch damper reduces the torque and vibration caused by engaging the clutch pedal's effect on the rest of the engine system. It is modeled as parallel torsional spring and damper. It is described as following equation:

$T_{d}=k^{*} \theta+d^{*} w$

Where, $T_{d}$ is the torque transmitted by the clutch damper, $k$ and $d$ is the stiffness and damper of the clutch damper, respectively, $\theta$ and $w$ is the relative angle and relative rotational speed of the two plates, respectively. 


\subsection{Clutch Model Assembly}

The clutch library includes clutch components, such as lever, release bearing, clutch damper, diaphragm, clutch plate, etc., which is can be seen in Fig. 2.

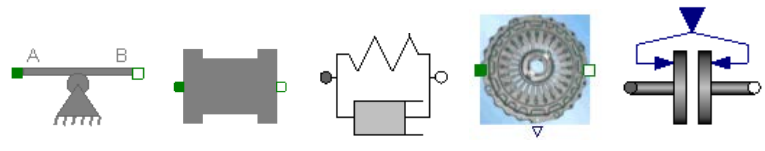

Fig. 2 The clutch library

According to the subsystem model of clutch system mentioned above, a clutch model assembly was built by graphic user interface, as can be seen in Fig.3. The model includes clutch lever, throw-out bearing, diaphragm spring, clutch plate, clutch damper, etc. Where, the port $A$ is connected to the engine, the port $\mathrm{B}$ is connected to the input shaft of the gearbox, and the port $\mathrm{C}$ is connected to the clutch actuation system.

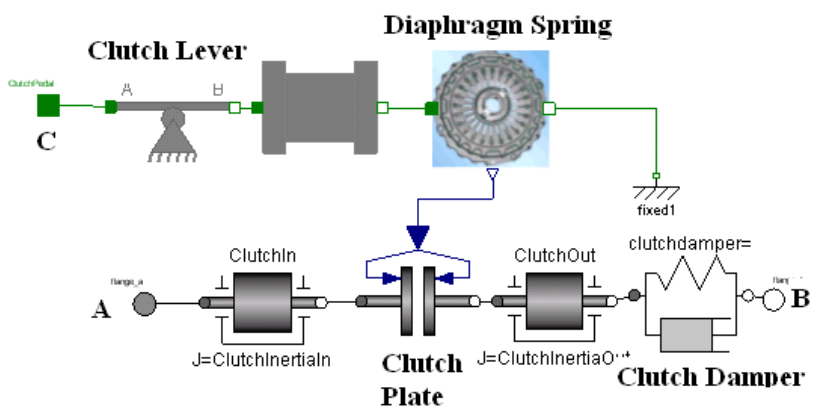

Fig.3 The clutch model

\section{GearBox Model}

The gearbox provides speed and torque conversions from a rotating power source to another device using gear ratios. The gearbox presented in this paper was equipped on heavy truck with 14 speeds. The gearbox included front sub-gearbox assembly, main gearbox assembly, and rear sub-gearbox assembly, which is planetary gearbox. The gear model, planetary gearbox model and synchronizer model will be introduced in the following.

\subsection{Gear Model}

A gear is a rotating machine part having cut teeth, or cogs, which mesh with another toothed part in order to transmit torque. The gear model is described as:

$$
\begin{aligned}
& T_{\text {in }}=T_{\text {out }}+r^{*}\left(F_{1}+F_{2}\right) \\
& \omega_{\text {in }}=\omega_{\text {out }}
\end{aligned}
$$

$$
v_{1}=v_{2}=r^{*} w_{i n}
$$

Where, $T_{\text {in }}$ is the torque acted on the input shaft, $T_{\text {out }}$ is the output torque, $\omega_{\text {in }}$ and $\omega_{\text {out }}$ are the rotary speed of the gear, $F_{1}$ and $F_{2}$ are the force acted on the gear teeth, $v_{1}$ and $v_{2}$ are the velocity of the gear teeth, and $r$ is the gear radius.

The gear library can be seen in Fig.4.

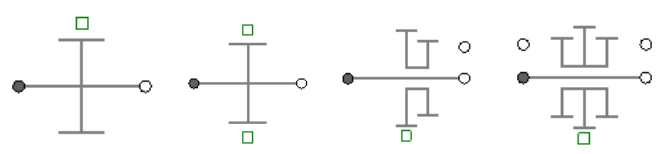

Fig. 4 The gear library

\subsection{Planetary Gearbox}

The planetary gear box is an ideal gear without inertia, elasticity, damping or backlash consisting of an inner sun wheel, an outer ring wheel and a planet wheel located between sun and ring wheel. The bearing of the planet wheel shaft is fixed in the planet carrier. The component can be connected to other elements at the sun, ring and/or carrier flanges. The planetary gearbox is described as follows:

The resulting torque on the ring gear is:

$$
T_{1}=\frac{r_{2}}{r_{2}-r_{1}} * T_{3}
$$

The rotary velocity of the planet carrier is:

$$
\omega_{3}=\frac{r_{2}}{r_{2}-r_{1}} * \omega_{1}+\frac{r_{1}}{r_{2}-r_{1}} \omega_{2}
$$

The resulting torque on the planet gear is:

$$
T_{2}=\frac{r_{1}}{r_{2}-r_{1}} * T_{3}
$$

Where, $T_{1}, T_{2}$ and $T_{3}$ is torque on the ring gear, the planet carrier and the planet gear, respectively, $\omega_{1}$, $\omega_{2}$ and $\omega_{3}$ is rotary velocity of the ring gear, the planet carrier and the planet gear, respectively, $r_{1}$ is the radius of the planet gear, $r_{2}$ is the radius of the ring gear. The planetary gear can be seen in Fig.5.

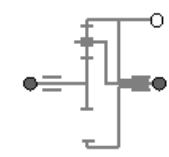

Fig. 5 The planetary gear

\subsection{Synchronizer Model}

The synchronizer is the most important shifting component in a gearbox. The functions of a synchronizer are: making disappear the angular velocity difference between the synchro hub and the gear to be engaged, impeaching the engagement of the gear 
while the angular velocity difference exists, and connecting hub and gear, by gear splines, via sleeve, in order to allow power transmission when the gear changing is realized [11].

However, the dynamical behaviour of these three mechanical subsystems is rather complicated to simulate because of the large number of elements. It is not easy to study the entire gear-changing process in detail [12]. So some simplifications were taken on the synchronizer model. In this paper, the synchronizer model was considered as a clutch plate model mentioned above. And the transmission torque is:

$$
\mathrm{M}=\frac{\mu \mathrm{F}_{m}}{\sin \alpha}
$$

Where $\mu$ friction coefficient between conical surfaces of the ring and the gear, $\alpha$ is the taper angle of the cone ring, $r_{m}$ is mean radius of the cone, $F$ is the gearshift force calculated by the gear actuator model. More details about the synchronizer can be referred to paper $[12,13]$.

The synchronizer library includes thrust piece, gear mesh, bumper stop, friction cone, etc., which is can be seen in Fig.6. The synchronizer model was shown in Fig.7.

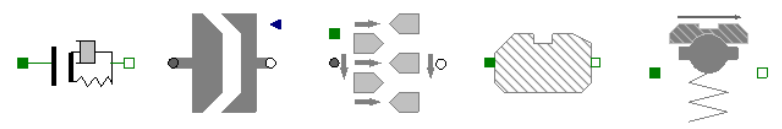

Fig. 6 The synchronizer library

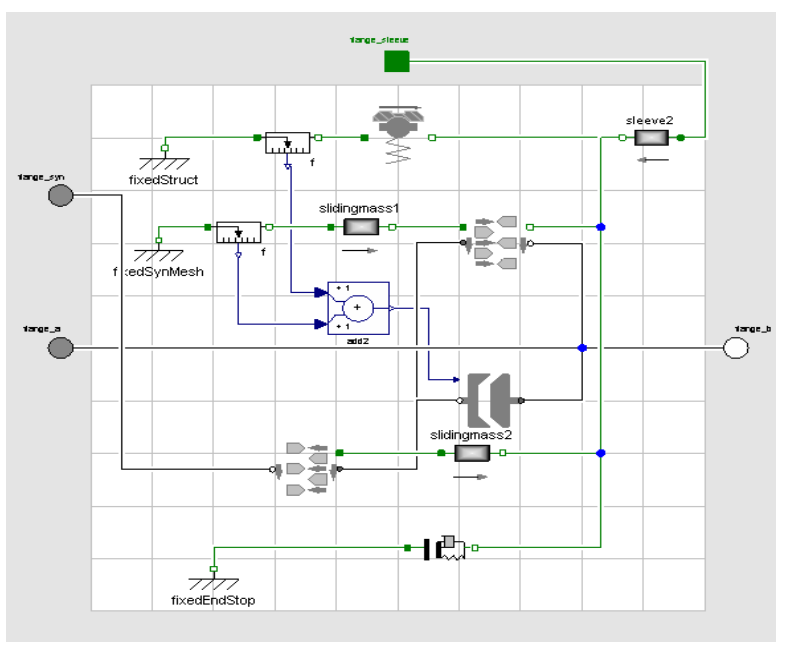

Fig. 7 The synchronizer model

\subsection{Gearbox Assembly Model}

The gearbox presented in this paper was a 14-speed gearbox. According to the subsystem model mentioned above, a gear box model assembly was built by the structure of the gearbox, as can be seen in Fig.8. The model includes gears, synchronizers, pla- netary gearbox, gear lever, gear efficiency, etc. Where, the port A is connected to the clutch, the port $\mathrm{B}$ is connected to the output shaft of the gearbox, and the port $\mathrm{C}$ is connected to the gear actuator system, such as gear shift actuator, gear select actuator.

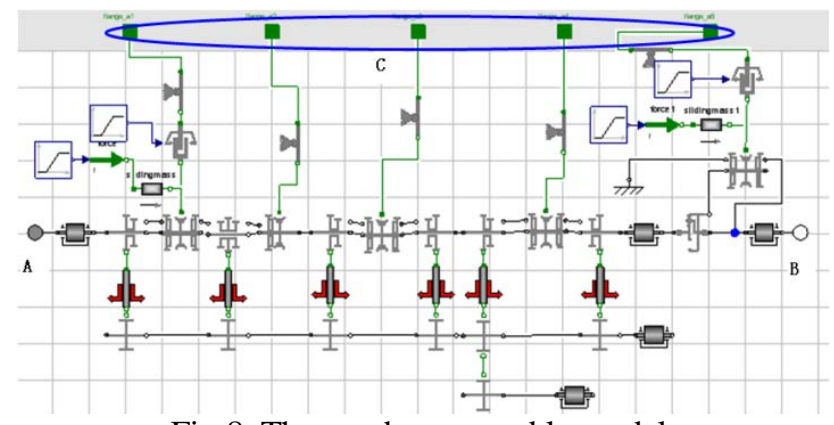

Fig.8 The gearbox assembly model

\section{Actuator Model}

The pneumatic actuator of AMT is consists of pneumatic source, pneumatic actuator of clutch, gear select actuator, gear shift actuator, and other components. The clutch actuator was controlled by the clutch control logic to exert a displacement on the clutch lever, and make the clutch engaged or disengaged by the control logic. The gear select actuator and shift actuator were connected to the gear box, and exert a force on the gear box to select or shift the gears according by the gearbox control logic. The pipe is neglected because it is very short.

The flow chart of the pneumatic actuator can be seen in Fig.9. Where, the reservoir is the air source of the pneumatic actuation system, the clutch cylinder is connected to the clutch lever, the gear shift cylinder, the gear select cylinder, the front and rear subgearbox cylinder were connected to the gearbox. The cylinder was controlled by the directional control valves to move to certain position with certain velocity. The valves were get signals by the control logic.

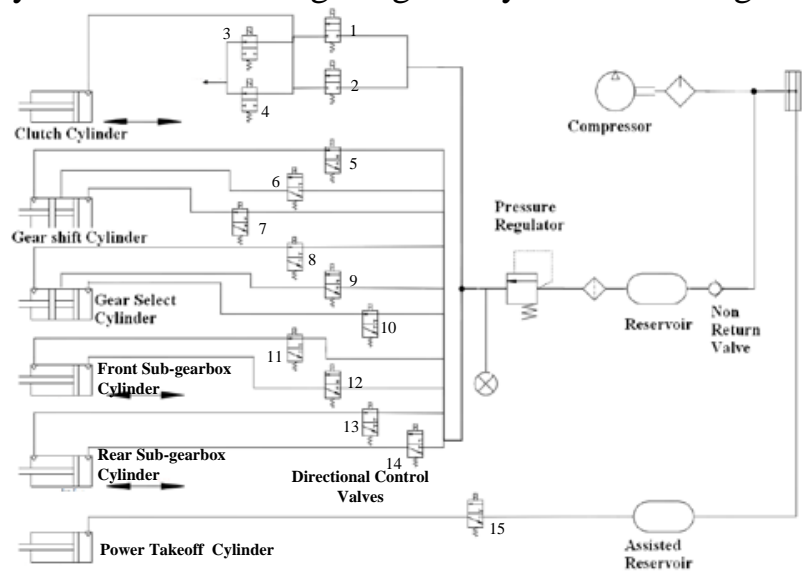

Fig.9 The Flow chart of the pneumatic actuator 


\section{Simulation and Results}

To analysis the performance the AMT systems, the simulation about the clutch actuation system, the synchronizer and overall vehicle equipped AMT assembly were carried out in the following.

\subsection{Synchronizer Simulation}

In this model, the synchronizer body and sleeve have an initial rotational speed of $1500 \mathrm{rpm}$ and the idle gear has an initial speed of $1000 \mathrm{rpm}$. The sleeve moves to the teeth of the synchronizer ring, the synchronizer body and sleeve synchronize with idle gear, the sleeve moves further until it meets the teeth to the idler gear and finally the idler gear is positively locked.

Fig. 10-12 shows the work phase of the synchronizer. When the synchronize ring was shifted, the normal force on the cone ring will increase, then down to zero, and the synchronizer ring will hold at the gearmesh position for some time before the two side achieved the same speed.

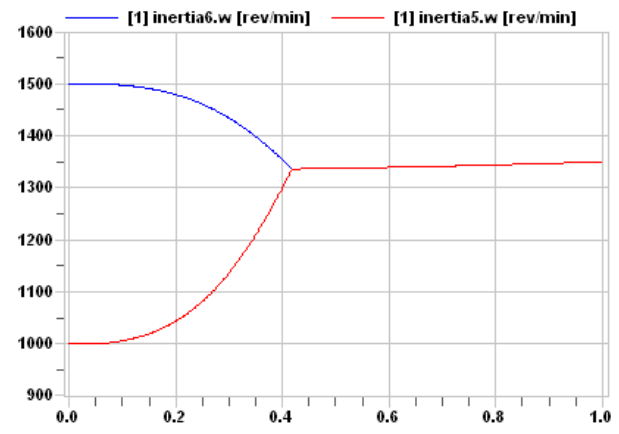

Fig.10 Rotational speed of two sides

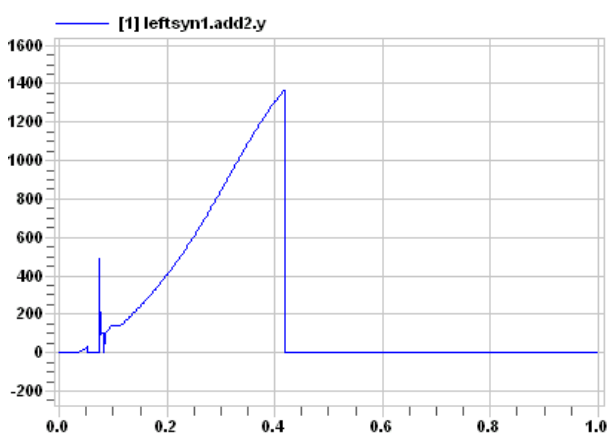

Fig.11 Normal force acted on the cone ring

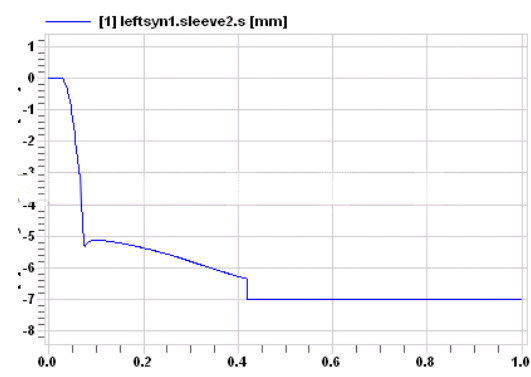

Fig.12 displacement of the synchronizer ring

\subsection{Clutch System Actuation Simulation}

This model tested the clutch response when the clutch actuator pushed the clutch lever, and disengage the clutch plate. The model can be seen in Fig.13. Fig.14 shows the control signal of clutch actuator. Fig.15-17 shows the performance of the clutch. The red line was the simulation results, and the blue line is the experiment results. The simulation results fit the experiment results very well.

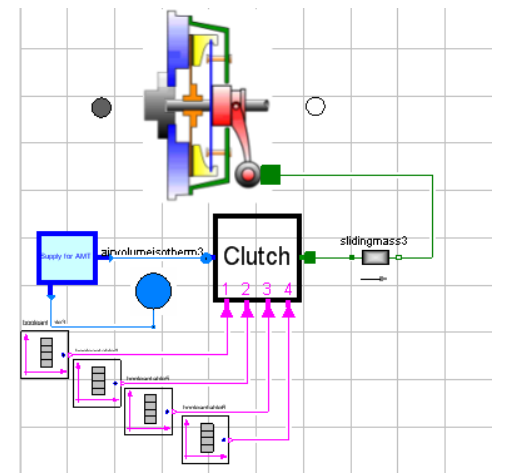

Fig.13 Clutch System Actuation Simulation

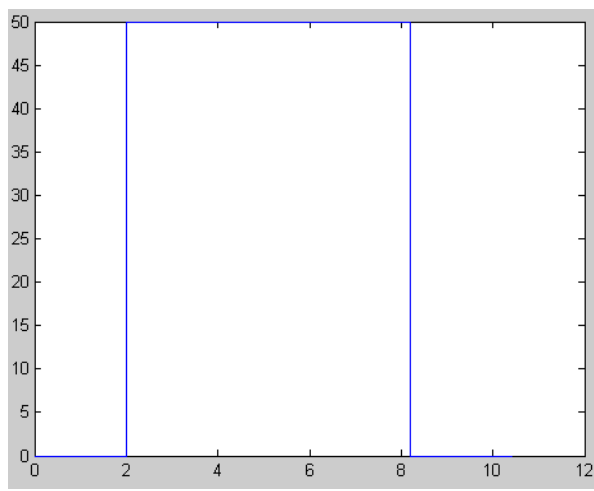

Fig.14 Input signal of clutch actuator 


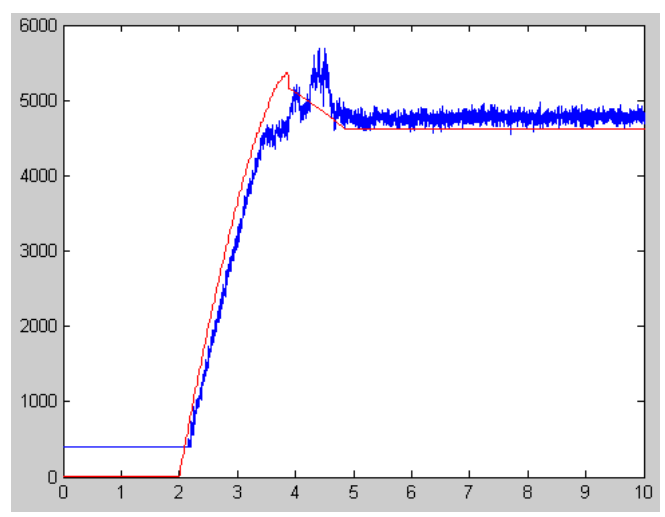

Fig.15 The displacement on the clutch lever

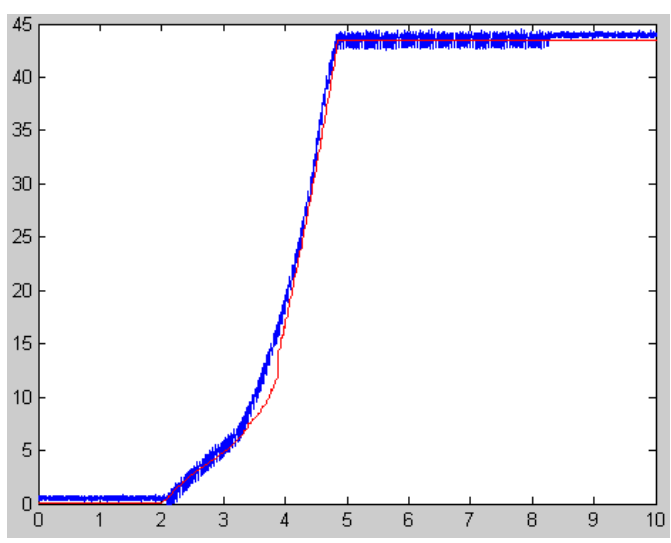

Fig.16 The Force on the clutch lever

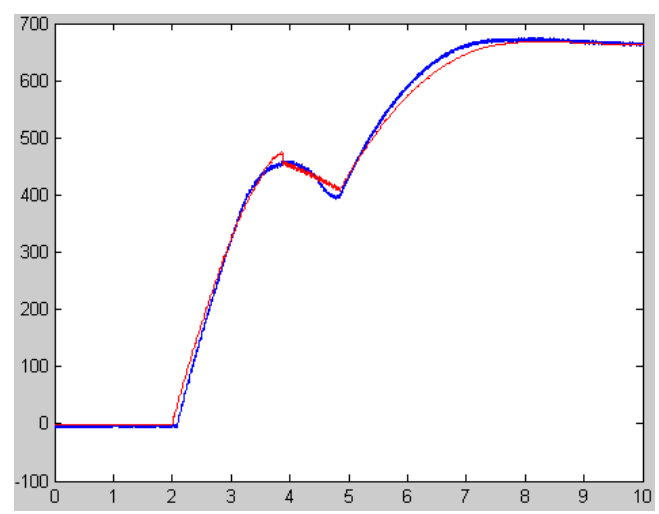

Fig.17 The pressure in the cylinder

\subsection{Co-simulation with Vehicle Model}

According to the topology of the AMT, the pneumatic actuator, clutch, gear box model were assembled together to get the AMT model, as can be seen in Fig.18.

The vehicle model was developed with Matlab/Simulink. To connect the AMT model with the overall vehicle model, the modelica model must be translated to simulink model. MWorks can complile the modelica model to s-function model, seen in Fig.19.

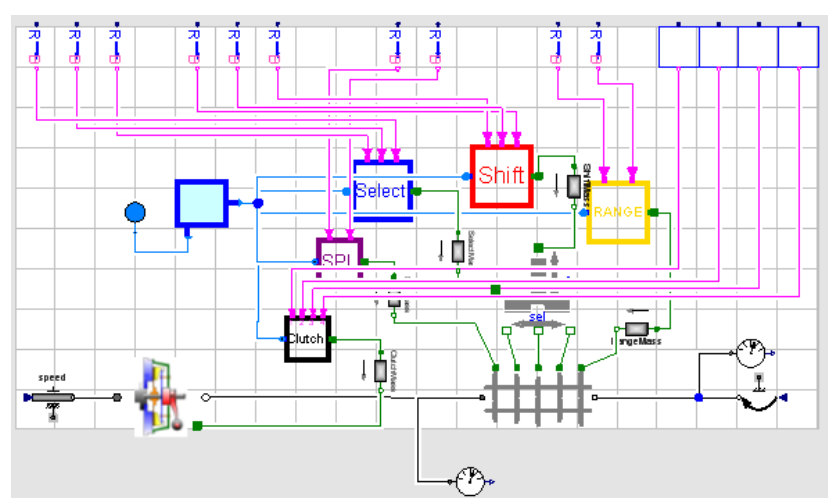

Fig.18 The pressure in the cylinder

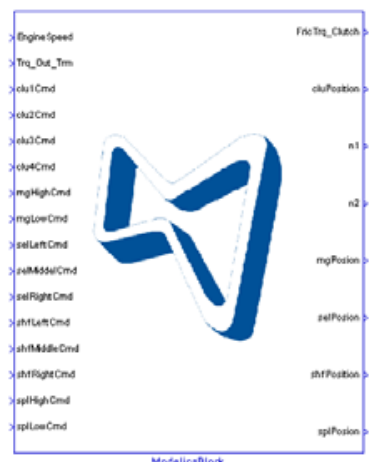

Fig.19 The s-function model

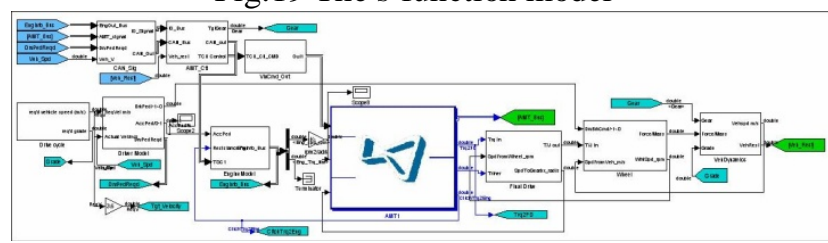

Fig.20 The overall vehicle model

The input signal to AMT model include the clutch command, select gear command, shift gear command, front sub-gearbox shift command, rear sub-gearbox shift command, engine speed and torque, etc. The output signal to the vehicle model and control logic include the clutch cylinder position, the gear select actuator position, the gear shift actuator position, the front sub-gearbox shift actuator position, the rear sub-gearbox shift actuator position, output speed of the gearbox, etc. The overall vehicle model can be seen in Fig.20. The simulation was carried out to follow a given speed.

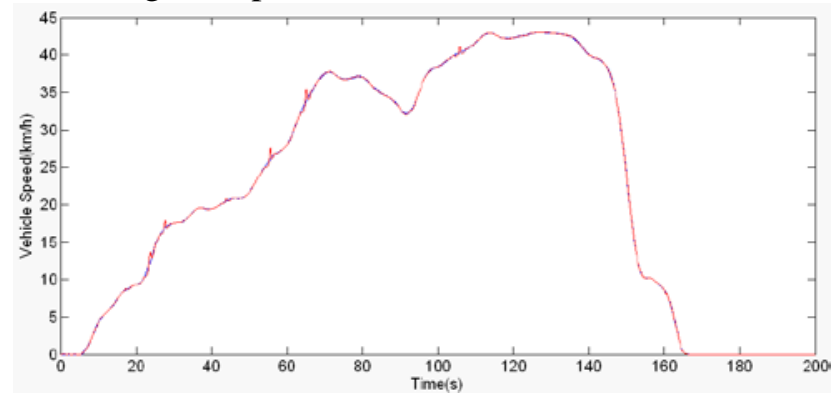

Fig.21 The vehicle speed 


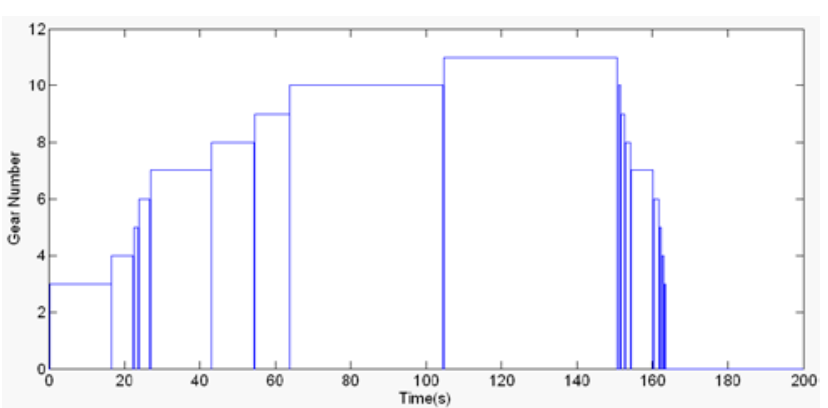

Fig.22 Gear number

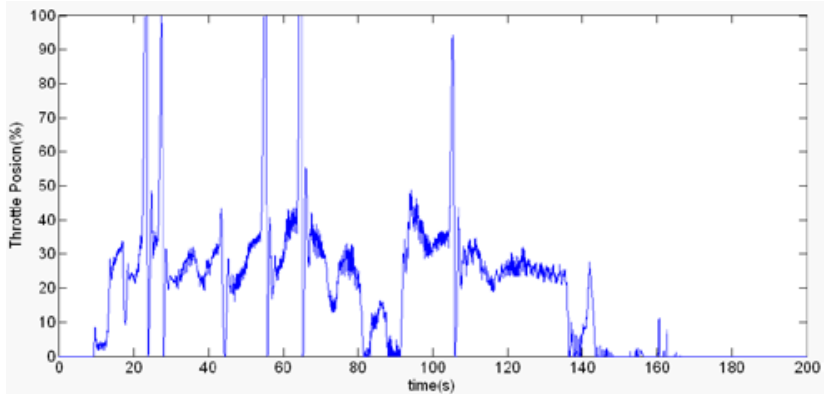

Fig.23 Throttle position

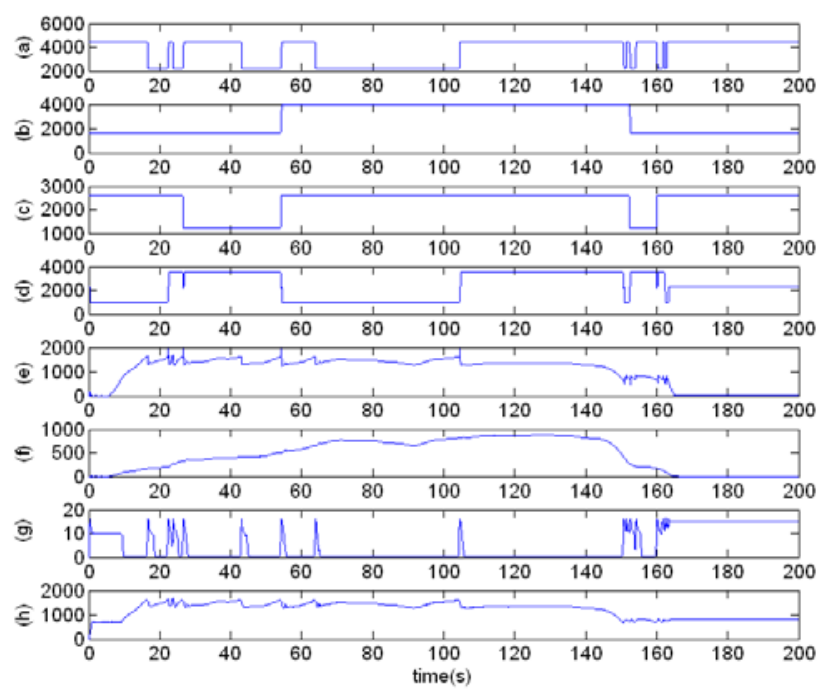

Fig.24 The performance of AMT

Fig. 21 shows the required vehicle speed and the actual vehicle speed. The red line is the required vehicle speed and the blue line is the simulation vehicle speed. Fig.22 shows the gear number, and Fig.23 shows the throttle position. Fig.24 shows the performance of the AMT model. Fig. $a$ is the front subgearbox shift actuator position, Fig. $b$ is the rear subgearbox shift actuator position, Fig. $c$ is the gear select actuator position, Fig. $d$ is the gear shift actuator position, Fig. e is the input speed of the gearbox, Fig. $f$ is the output speed of the gearbox, Fig. $g$ is the clutch cylinder position, and Fig. $\mathrm{h}$ is the engine speed.

\section{Conclusions and Further Study}

The paper addressed the problem of modeling AMT system. A detailed model of the driveline of a heavy truck with automated mechanical transmission was been developed. It considers both the dynamics of the transmission shafts, and the servo-actuated clutch and gearbox. Detailed models of the pneumatic actuators and its effects on driveline behavior and on performance during gear shift can be evaluated. The simulation results show that the detailed model can be used to estimate the influence of the clutch and gearbox actuation systems on the vehicle performance. The influence affected by the actuator on the dynamic behavior of the vehicle, such as shift quality, driveability, fuel economy, acceleration, etc. will be researched in the future.

\section{Acknowledgement}

This work was supported by the National High-Tech R\&D Program, China (No. 2009AA044501).

\section{References}

1. Hiroshi K., Naoyuki O. Takashi O. and Masaru Y. Next-generation Fuel-efficient Automated Manual Transmission. Hitachi Review, 2004, Vol. 53, No. 4.

2. Florêncio D. and Assis E. The Manual Transmission Automated - Gearshift Quality Comparison to a Similar Manual System. SAE paper 2004-01-3363.

3. Turner A. J. and Ramsay K. Review and Development of Electromechanical Actuators for Improved Transmission Control and Efficiency. SAE paper 2004-01-1322.

4. Franceso V., Luigi I., Adolfo S. and Maurizio T. Modeling Torque Transmissibility for Automotive Dry Clutch Engagement. 2008 American Control Conference, Washington, USA, June 11-13, 2008

5. Zhao Y., Chen L., Zhang Y. and Yang J. Enhanced Fuzzy Sliding Mode Controller for Automated Clutch of AMT Vehicle. SAE paper 2006-01-1488.

6. Liu F., Li Y., Zhang, J., Huang H. and Zhao H. Robust Control for Automated Clutch of AMT Vehicle. SAE paper 2002-01-0933.

7. Lucente G., Montanari M., Rossi C. Modelling of an automated manual transmission system. Mechatronics, 2007, No. 17, pp.73-91.

8. Zhao L., Zhou Y. and Zheng L. Modeling and Simulation of AMT Clutch Actuator Based on SimulationX. Computational Intelligence and Software Engineering, 2009, pp.1-5.

9. Fritzson P., Vadim V. Modelica -- A Unified ObjectOriented Language for System Modeling and Simula- 
tion. Proceedings of the 12th European Conference on Object-Oriented Programming, 1998, pp.67 - 90.

10. Zhou F, Chen L. and Wu Yi., etc. MWorks: a Modern IDE for Modeling and Simulation of Multidomain Physical Systems Based on Modelica. Modelica 2006, September 4 th $-5^{\text {th }}$, pp. 725-732.

11. Manish K., Taehyun S., Zhang Y. Shift dynamics and control of dual-clutch transmissions. Mechanism and Machine Theory, 2007, Vol.42, pp.168-182

12. Lovas L. and Play D. etc. Modelling of gear changing behavior. Periodica Polytechnica Ser. Transp. Eng. 2006, Vol. 34, No. 1-2, pp. 35-58.

13. Lovas L., Play D., Marialigeti J. and Rigal J. F. Mechanical behaviour simulation for synchromesh mechanism improvements. Proceedings of the Institution of Mechanical Engineers, Journal of Automobile Engineering, 2006, Vol. 220, No. D7, pp. 919-945. 